\title{
Development of a Single Screw Extruder For The Production of Wood-Plastic Composite
}

\author{
Omoniyi T.E, Adesanya D.E \\ temidayoomoniyi@gmail.com \\ Department of Wood Products Engineering \\ University of Ibadan
}

\begin{abstract}
A wood-plastic composite extruder (single screw extruder) was designed, fabricated and evaluated to recycle and produce a product for non-structural purposes. The extruder is separated into four units: The feeding, conveying, heating and forming unit. The material is fed by gravity into a hopper and conveyed by a screw conveyor at a predetermined speed through a heated barrel and the extrudate is metered through the breaker plate and the die. The output rate is directly related to the screw speed. Test samples were produced with the machine and experimental tests were conducted to determine its suitability for non-structural purposes and applications. The performance evaluation test on the machine shows that at speeds of 4rpm and $50.25 \mathrm{rpm}$, the machine performs at $87 \%$ and $82 \%$ efficiency respectively which makes it effective for production. The machine takes a maximum of $5 \mathrm{mins}$ to recycle a batch with an average capacity of $14.04 \mathrm{~kg} / \mathrm{hr}$ at $4 \mathrm{rpm}$ and $17.55 \mathrm{~kg} / \mathrm{hr}$ at $50.25 \mathrm{rpm}$. The machine conserves cost and energy due to low specific mechanical energy consumption of $191.21 \mathrm{~kJ} / \mathrm{kg}$.
\end{abstract}

Keywords-Wood-Plastic Composite, Single Screw Extruder, Renewable Materials, Efficiency, Capacity, Specific Mechanical Energy.

\section{INTRODUCTION}

$I^{2}$ ndustrial logging and exploitation of the world's primary forest are rapidly destroying the habitats of animal and plant species which in turn lead to the depletion of the earth's ozone layer [4]. The destructive exploitation of hardwoods is also responsible for this widespread deforestation.

F. A. Author is with the National Institute of Standards and Technology, Boulder, CO 80305 USA (corresponding author to provide phone: 303-5555555; fax: 303-555-5555; e-mail: author@ boulder.nist.gov).

S. B. Author, Jr., was with Rice University, Houston, TX 77005 USA. He is now with the Department of Physics, Colorado State University, Fort Collins, CO 80523 USA (e-mail: author@lamar. colostate.edu).

T. C. Author is with the Electrical Engineering Department, University of Colorado, Boulder, CO 80309 USA, on leave from the National Research Institute for Metals, Tsukuba, Japan (e-mail: author@nrim.go.jp).
Wood based-industries generate sawdust from sanding, cutting, drilling and milling operations where wood is removed from a finished product. Wood dusts are very fine particles that are generated during sanding or other machining operations; it is often collected in filter bags or dust collectors [7]. Activities of Plastics Manufacturers such as manufacturing, processing, transportation and consumption add stress to the environmental system by accumulating stock of waste [2]. Today, polythene (and polypropylene), a polymer has been put to different use as containers, wrappers, sachets, bags and packages. Its extensive use has resulted in its litter in every nook and cranny of our roads, markets and other nondesignated places. This has caused negative impacts on our environment as they are non-biodegradable.

More than thirty years ago, there has been an increasing concern in wood polymer composites and its applications have been growing and expanding. Environmental issues and high demands on lower material costs are the driving forces behind the increasing need of renewable materials. The accumulation of un-managed wastes especially in developing countries has resulted in an increasing environmental concern.

In Nigeria, recycling is highly necessary so as to reduce the volume of waste generated and also to serve as a means to solving environmental degradation problems as these wastes are currently disposed in sanitary landfills or openly dumped into uncontrolled waste pits and open areas. The Environmentalists including the Engineers have been challenged to develop technically reasonable solutions to environmental waste problems.

Wood-plastic composites (WPC) are made up of two main constituents, though both are polymer based, they are very different in structure, performance as well as origin. Polymers are high molecular weight materials whose performance is largely determined by its molecular composition. In WPCs, the polymer matrix forms the continuous phase surrounding the 
wood component. These polymers are typically low cost commodity polymers which flow easily when heated and allowing considerable processing flexibility when wood is combined with them. Thus due to the low thermal stability of wood, only polymers with processing temperatures lower than $200^{\circ} \mathrm{C}$ can be used in WPC. These polymers tend to shrink and swell with temperature but absorb little moisture and can be effective barriers to moisture intrusion in a well designed composite. The most common polymers used are polyethylene (PE), polypropylene (PP) and polyvinylchloride (PVC).

As a result, the objective of this work is to design and construct a single screw extruder machine that can be used to produce Wood-Plastic Composites from wood wastes and plastic that litters, then the performance evaluation of the machine.

\section{EXTRUDER DESCRIPTION}

The extruder is an assembly of a screw-shaft system being rotated by a medium speed electric motor. The screw is housed in a heated cylindrical barrel that employs two processing stages, melting and metering, and a vent section to remove volatiles. The material is fed through a gravity hopper. The melting/mixing mechanism is through barrel heating and screw shearing while the extrudate is metered through the breaker plate and die which gives the product its profile. The output rate is directly related to the screw speed: an increase in screw speed will result in an increased throughput. A pulley and vbelt system is attached to an electric motor to control the screw speed which in turn controls the output rate.

\section{MATERIALS AND METHODS}

The materials used for the project work were a set of locally sought machine parts for the fabrication of the Single Screw Extruder, and waste water sachets, plastic bottles and sawdust for the performance evaluation.

\section{A. Design of the Single Screw Extruder}

The design of the Single Screw Extruder was adapted from a number of literatures [9] [10].

\section{B. Design Parameters}

In order to achieve the set objectives, the extruder is separated into five units i.e. the feeding, conveying, heating, power unit and forming unit. Each of this unit performs specific functions.

\section{B.1 Feeding Unit}

This unit is made up of the hopper where the materials of production is fed and transported from the top (inlet), down to the feed throat of the extruder. The material mixture meets the auger at the feed throat. There are vertical and horizontal forces present in the hopper and act on the inside wall of the hopper. Therefore, since the operation will be done in batches, the size selected should be considerably small to increase efficiency and also large enough to ensure high production rate.

\section{B.2 Conveying Unit}

This unit is made up of the screw conveyor also known as the auger. It conveys the mixture that are fed down from the hopper through the feed throat down to the die, with the help of the electric motor, belt and shaft system, passing them through various heating zones. The screw has a pitch of $50 \mathrm{~mm}$ i.e. the material moves a distance of $50 \mathrm{~mm}$ in a revolution. The screw also enables mixing required during the process and to generate a stable and homogenous supply of the mixture to the die.

\section{B.3 Heating Unit}

The heating unit is made of four heating bands wrapped round the body of the barrel and connected to a power source. The heater provides heat to melt the plastic and is set at $180^{\circ} \mathrm{C}$ to avoid burning the wood content which undergoes thermal degradation at $220^{\circ} \mathrm{C}$.

\section{B.4 Power Unit}

This unit is made up of the electric motor, V-belt and pulley and the shaft.

\section{B.5 Forming Unit}

This unit is made up of the screen pack, breaker plate and the die. At this section, the mixture is already in molten form and flows through the screen pack where it is screened to remove impurities and then to the breaker plate which helps to increase the back pressure for proper mixing of the molten and finally to the die, that is attached to the extruder via a adapter changing the direction of flow where it takes the final shape.

\section{Design Requirements}

The considerations made in the design of the single-screw extruder to enhance effectiveness, safety and affordability include that the power requirement should be minimal, the component should be easy to dismantle, assemble and easily replaced in case of any damage or failure, the design size will be small-scaled for easy construction at minimum cost and simplicity without compromising standards. The materials of construction used were locally sourced and dependent on suitability, availability, cost effectiveness and strength. 
The mass of the polymer and wood content to be gravity fed into the hopper is determined as;

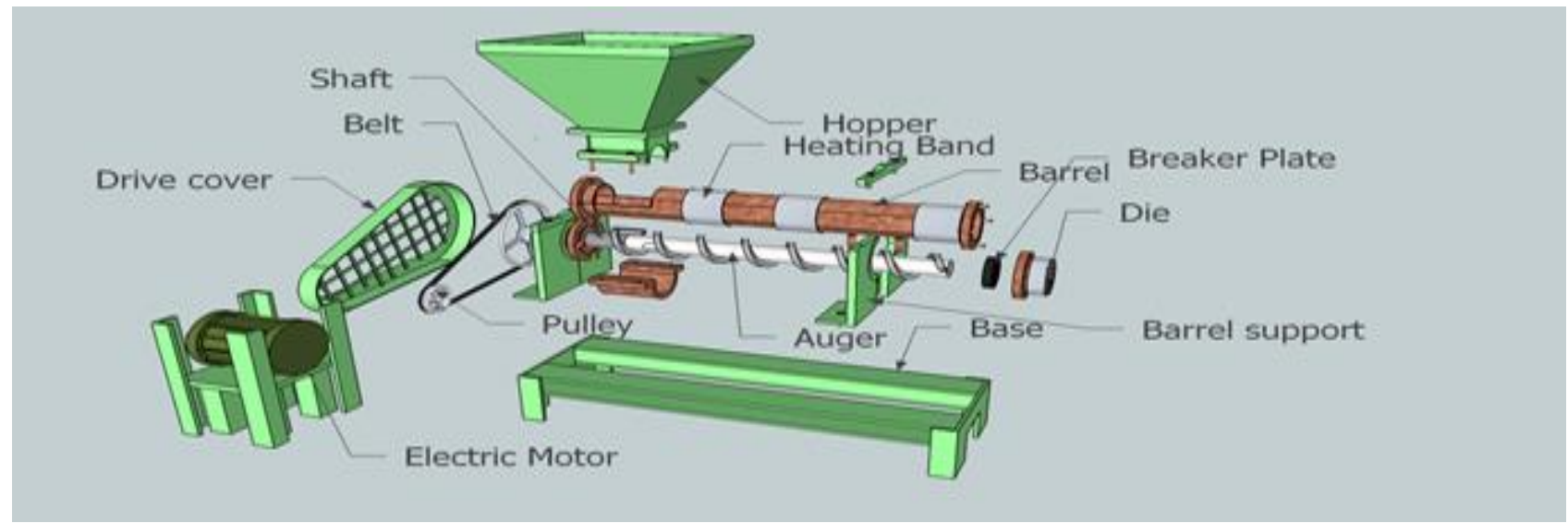

Fig. 1: Exploded view of the Extruder

\section{Design Analysis}

Assumptions, established theories, principles and engineering equations were used to evaluate the necessary design parameters, strength and size of materials for consideration in the selection of the various machine parts so as to mitigate failure during working span of the machine.

\section{D.1. Design of Hopper}

The maximum volume of the composite material that the machine can handle in one operation is calculated thus from the diagram shown; -

The top diameter is taken as 3 times the lower diameter [10],

From Frustum law,

$V=\frac{1}{3} \pi R^{2}(H+h)-\frac{1}{3} \pi r^{2} H$

$\mathrm{D}=45 \mathrm{~cm}=0.45 \mathrm{~m}, \mathrm{~d}=15 \mathrm{~cm}=0.15 \mathrm{~m}, \mathrm{~h}=50 \mathrm{~cm}=0.5 \mathrm{~m}$

$\frac{\mathrm{H}}{\mathrm{r}}=\frac{\mathrm{h}+\mathrm{H}}{\mathrm{R}}=\frac{\mathrm{H}}{0.075}=\frac{0.5+\mathrm{H}}{0.225}$

$\mathrm{H}=0.25 \mathrm{~m}$

$\mathrm{V}=\left[\left(\frac{\pi \times 0.225^{2}}{3} \times(0.25+0.5)\right)-\left(\frac{\pi \times 0.075^{2} \times 0.25}{3}\right)\right]$

$=0.0383 \mathrm{~m}^{3}=38.3$ litres

$\mathrm{M}_{\mathrm{p}}=530.8 \mathrm{~kg} / \mathrm{m}^{3} \times 0.023 \mathrm{~m}^{3}=12.2 \mathrm{~kg}$

$\mathrm{W}_{\mathrm{p}}=\mathrm{M}_{\mathrm{p}} \times \mathrm{g}$ (g= acceleration due to gravity)

$W_{\mathrm{p}}=12.2 \times 9.81=119.68 \mathrm{~N}$

$\mathrm{M}_{\mathrm{w}}=112 \mathrm{~kg} / \mathrm{m}^{3} \times 0.015 \mathrm{~m}^{3}=1.68 \mathrm{~kg}$

$W_{\mathrm{w}}=1.68 \times 9.81=16.48 \mathrm{~N}$

Weight of composite $=119.68 \mathrm{~N}+16.48 \mathrm{~N}=136.16 \mathrm{~N}$

\section{D.2. Selection of Electric Motor}

An electric motor of the following specification was selected;

Power $=2 \mathrm{hp}(1.49 \mathrm{kw})$

Rotational speed $=268 \mathrm{rpm}$

\section{D.3. Design of Pulley}

In order to achieve the desired speed of the auger, variation of pulley is calculated using the equation of speed ratio shown below in the equation [8].

$\frac{D_{r}}{D_{m}}=\frac{N_{m}}{N_{r}}$

Where; $\mathrm{N}_{\mathrm{m}}=$ rotational speed of electric motor (268rpm) [10].

$\mathrm{N}_{\mathrm{r}}=$ rotational speed of rotor

$\mathrm{D}_{\mathrm{r}}=$ diameter of rotor pulley (driven pulley, $400 \mathrm{~mm}$ )

$\mathrm{D}_{\mathrm{m}}=$ diameter of motor pulley (driver pulley, $75 \mathrm{~mm}$ )

$N_{r}=\frac{D_{m} \times N_{m}}{D_{r}}=\frac{75 \times 268}{400}=50.25 \mathrm{rpm}$

But, volume of hopper $=$ volume of polymer + volume of wood content

Volume of polymer $=\frac{60}{100} \times 0.0383=0.023 \mathrm{~m}^{3}$

Volume of wood content $=\frac{40}{100} \times 0.0383=0.015 \mathrm{~m}^{3}$

\section{D.4. Design of the Belt Drive}

Pitch line velocity of the belt is given as;

$\mathrm{V}=\frac{\pi D N}{60}[5]$

Velocity of the belt, $\mathbf{V}$ is calculated thus $\mathrm{D}=$ Diameter of driver $(75 \mathrm{~mm})$ 
$\mathrm{N}=$ Revolutions per minute of the driver (268rpm)

$\mathrm{V}=\frac{\pi \times 0.075 \times 268}{60}=1.05 \mathrm{~m} / \mathrm{s}$

The type of drive been used is the open belt drive whose length was found using the relation below;

$\mathrm{L}=\pi(r 1+r 2)+2 X+\frac{(r 1-r 2)^{2}}{X}[5]$.

$r 1 \& r 2=$ radius of smaller and larger pulley $(37.5 \mathrm{~mm}$, $200 \mathrm{~mm})$

$\mathrm{X}=$ distance between the two pulleys $(400 \mathrm{~mm})$

$\mathrm{L}=\pi(0.0375+0.2)+2(0.4)+\frac{(0.0375-0.2)^{2}}{0.4}=$

$1.61 \mathrm{~m}$

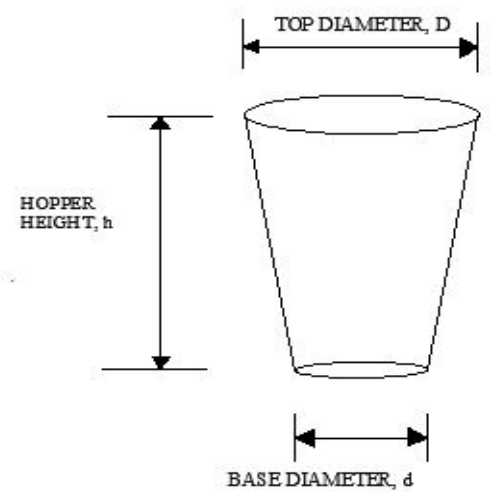

a.

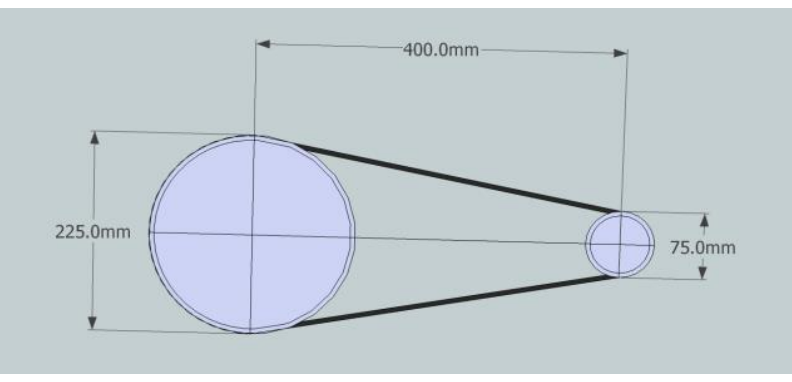

c.

Fig. 2: Schematic diagrams of the belt and pulley system

Power transmitted by belt drive is given as;

$\mathrm{P}=\left(T_{1}-T_{2}\right) V$ (watts) [5].

$\mathrm{T}_{1}=$ Tension in the belt on the tight side

$\mathrm{T}_{2}=$ Tension in the belt on the slack side

$\mathrm{V}=$ Velocity of the belt

Ratio of driving tension for $\mathrm{V}$-belt drive;

$2.3 \log \frac{T_{1}}{T_{2}}=\mu \theta \operatorname{cosec} \beta[5]$.

$\mu=$ coefficient of friction between belt and pulley $\theta=$ angle of contact in radians

$\beta=$ half of the groove angle (Groove angle, $2 \beta$, is usually between $32^{\circ}$ to $38^{\circ}$ to avoid loss of power due to pulling of belt and excessive wear due to friction and heat) [5]

Let's assume $2 \beta$ of $34^{\circ}$, therefore $\beta$ is $17^{\circ}$

$\sin \alpha=\frac{R_{1}-R_{2}}{X}$ [5].

$\operatorname{Sin} \alpha=\frac{200-37.5}{400}=0.406$

$\alpha=\sin ^{-1}(0.406)=24^{\circ}$

Therefore, angle of contact is;

$\theta=\left(180^{\circ}-2 \alpha\right) \frac{\pi}{180} \mathrm{rad}$, for open belt drive [5].

$\theta=(180-2(24)) \times \frac{\pi}{180}=2.3 \mathrm{rad}$

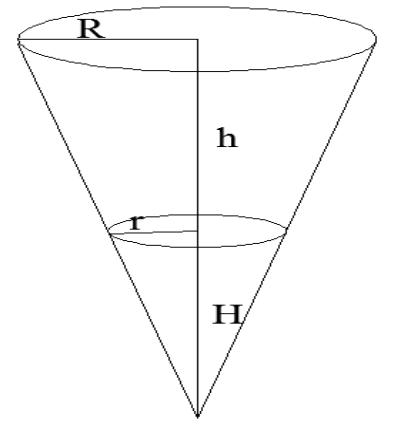

b.

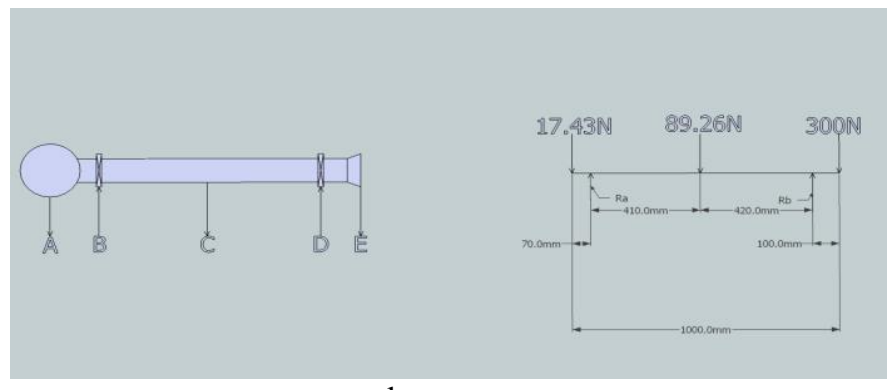

d.

The coefficient of friction $(\mu)$ between the rubber belt and the dry cast iron pulley is given as 0.3

Assuming power to be transmitted is given as $1.49 \mathrm{kw}$, therefore

$$
\begin{aligned}
& 1.49=\left(T_{1}-T_{2}\right) 1.05 \\
& T_{1}-T_{2}=1.42
\end{aligned}
$$

From equation (6)

$$
2.3 \log \frac{T_{1}}{T_{2}}=0.3 \times 2.3 \times \operatorname{cosec} 17^{\circ}
$$




$$
\begin{aligned}
& \log \frac{T_{1}}{T_{2}}=\frac{0.3 \times 2.3 \times 3.42}{2.3} \\
& \frac{T_{1}}{T_{2}}=10^{1.026}=10.62 \\
& \mathrm{~T}_{1}=10.62 \mathrm{~T}_{2} \\
& \mathrm{~T}_{1}=1.59 \mathrm{~N}, \mathrm{~T}_{2}=0.15 \mathrm{~N}
\end{aligned}
$$

Weight of screw $=20 \mathrm{~N}[10]$.

Weight of mixture $=136.16 \mathrm{~N}$

Total Weight $=20 \mathrm{~N}+136.16 \mathrm{~N}=156.16 \mathrm{~N}$

Die weight $=300 \mathrm{~N}$

Weight at point $\mathrm{A}=$ Weight of pulley + tension on tight and

slack sides $=17.43 \mathrm{~N}$

Therefore, $\mathrm{R}_{\mathrm{b}}+\mathrm{R}_{\mathrm{d}}=(17.43+156.16+300) \mathrm{N}$

Taking moments at point $\mathrm{B}$,

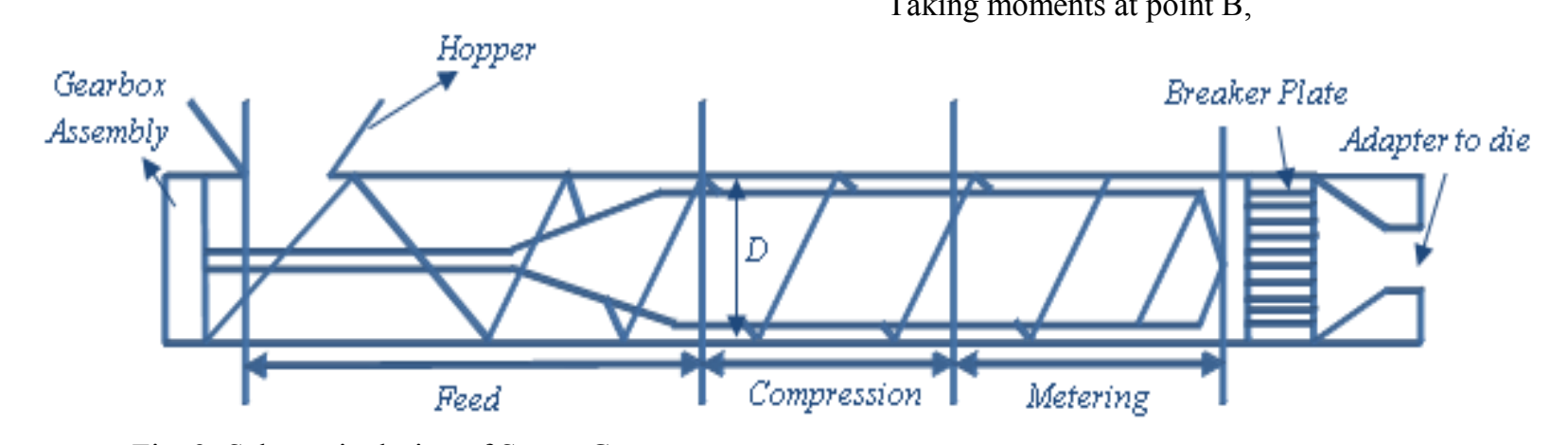

Fig. 3: Schematic design of Screw Conveyor

\section{D.5. Design of the Shaft}

The diameter of the shaft was determined using the following equations [5].

$\mathrm{T}_{\mathrm{e}}=\sqrt{(K m \times M)^{2}+(K t \times T)^{2}}$

$\mathrm{M}_{\mathrm{e}}=\frac{1}{2}\left(K m \times M+\sqrt{(K m \times M)^{2}+(K t \times T)^{2}}\right)$

(17)

$\mathrm{T}=\left(T_{1}-T_{2}\right) R$

$\mathrm{T}=\frac{\pi}{6} \times t \times d^{3}$

$\mathrm{M}=\frac{\pi}{32} \times \sigma \times d^{3}$

$\mathrm{T}_{\mathrm{e}}=$ equivalent twisting or torsion (torque)

$\mathrm{M}_{\mathrm{e}}=$ equivalent bending moment

$\mathrm{M}=$ bending moment

$\mathrm{T}=$ torsion or twisting moment

$\mathrm{d}=$ diameter

$t=$ shear stress, $42 \mathrm{Mpa}$ for shafts with allowance for keyways

[5].

$\sigma=$ normal stress, $84 \mathrm{Mpa}$ for shafts with allowance for keyways [5].

$\mathrm{R}=$ radius of bigger pulley

Using the equations above, to determine the twisting moment to which the shaft is subjected to, given $T_{1}=1.59 \mathrm{~N}, T_{2}=$ $0.15 \mathrm{~N}, \mathrm{R}=200 \mathrm{~mm}$, therefore,

$\mathrm{T}=(1.59-0.15) 200$

$\mathrm{T}=288 \mathrm{Nmm}=0.288 \mathrm{Nm}$

The load is assumed to be uniformly distributed along the effective length of the shaft, which comprises of the weight of the screw and that of the mixture;
$R_{d} \times 0.83+17.43 \times 0.07=156.16 \times 0.41+$ $300 \times 0.93$

$\mathrm{R}_{\mathrm{d}}=411.81 \mathrm{~N}$ and $\mathrm{R}_{\mathrm{b}}=61.78 \mathrm{~N}$

Weight of the bearings is $411.81 \mathrm{~N}$ and $61.78 \mathrm{~N}$

Resultant bending moment on the screw shaft is given as $M_{b}=300 \mathrm{~N} \times 0.93=279 \mathrm{Nm}$

Maximum bending moment on screw shaft is $279 \mathrm{Nm}$

$\mathrm{Me}=$

$\frac{1}{2}(1.5 \times 279+$

$\left.\sqrt{(1.5 \times 279)^{2}+(1.0 \times 0.71663)^{2}}\right)$

$=837 \mathrm{Nm}$

$d=\sqrt[\Xi]{\frac{32 x M}{\pi x \sigma}}=\sqrt[8]{\frac{32 x 837}{\pi x 84 x 10^{6}}}=0.04665 \mathrm{~m}$

$=46.65 \mathrm{~mm}$

$\mathrm{Te}=\sqrt{(1.5 \times 279)^{2}+(1.0 X 0.71663)^{2}}$

$=418.5 \mathrm{Nm}$

$d=\sqrt[\Xi]{\frac{T x 6}{\pi x \pi}}=\sqrt[\Xi]{\frac{418.5 x 6}{\pi x 42 \times 10^{6}}}=0.0267 \mathrm{~m}=26.7 \mathrm{~mm}$

Hence the standard diameter of shaft was chosen as $60 \mathrm{~mm}$ from the list of available size and of a bright mild steel material [5]. 


\section{D.6. Design of Screw Conveyor}

The screw is made up of 3 zones, which are: the feed zone, the compression zone, the metering (pumping) zone. The figure below shows a schematic diagram of the zones of the screw.

Since the material to be used consists of both wood and plastic material, L/D ( $\left.\frac{\text { useful flight lenght of screw }}{\text { screw diameter }}\right)$ ratio of the screw for thermoplastic extruder ranges from 25:1 to $35: 1$ [1] and the ratio chosen was 30:1, also extruders are described in terms of their screw (outside) diameter ranging from $25 \mathrm{~mm}$ to $300 \mathrm{~mm}$. [1] and the diameter was chosen as $30 \mathrm{~mm}$, hence the useful flight length of the screw is determined as;

Useful flight length of screw $=$

$\frac{\text { screw diameter } \times 30}{1}=\frac{30 \times 30}{1}=900 \mathrm{~mm}$

Analysis of flows in the extruder is also determined by the following equations;

Total flow $=\operatorname{Drag}$ flow $\left(Q_{d}\right)-$ Pressure flow $\left(Q_{p}\right)-$ Leak

flow $\left(Q_{2}\right)$.

Drag flow $\left(Q_{d}\right)=\frac{1}{2} \pi^{2} D^{2} N \sin \emptyset \cos \emptyset H[1]$

$\mathrm{D}=$ Screw diameter $=50 \mathrm{~mm}$

$\mathrm{H}=$ Channel depth of screw $=$

$\frac{\text { Diameter of barrel-Diameter of screw }}{2}$

But Internal diameter of barrel $=57 \mathrm{~mm}$

$\mathrm{H}=\frac{57-50}{2}=3.5 \mathrm{~mm}$

$\mathrm{N}=$ Screw rotational speed $=50.25 \mathrm{rpm}=0.84 \mathrm{rps}$

$\varnothing=$ Helix angle but Pitch $=\pi$ Dtan $\varnothing$, pitch $=50 \mathrm{~mm}$

$\varnothing=17.65^{\circ}$

Therefore, Drag Flow is $1.05 \times 10^{-5} \mathrm{~m}^{3} / \mathrm{s}$

Pressure flow $\left(Q_{p}\right)=\frac{\pi D H^{a} \sin ^{2} \emptyset}{12 \eta}\left(\frac{d p}{d l}\right)$

$d p=$ Pressure drop along extruder

$d l=$ Length of flow path

$\eta=$ Fluid viscosity $=m\left(T^{\circ} c\right) \gamma^{n-1}$

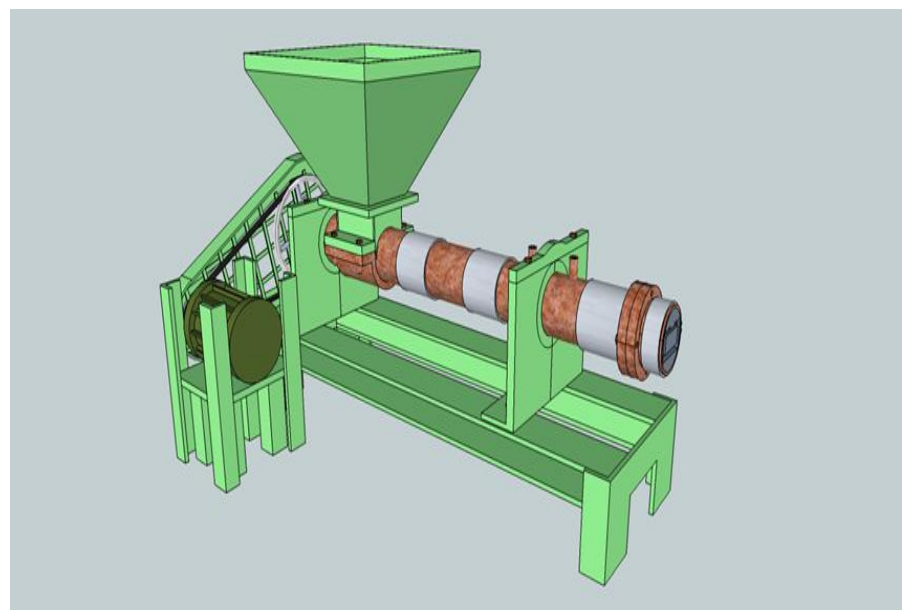

Fig. 4: Prototype of the Single Screw Extruder

Where, $\mathrm{m}=$ Consistency Index $=6 \times 10^{3}(\mathrm{~Pa}-\mathrm{s})^{n}$

$\mathrm{n}=$ Power Law Index; $\mathrm{n}=0.39$ (Kirubel et al, 2011)

$\gamma=$ Shear Rate $=\frac{\text { Velocity }}{\text { Channel depth }}=\frac{1.67 \times 10^{-4}}{3.5 \times 10^{-8}}=0.048 s^{-1}$

$\eta=7.6 \times 10^{6}$ pa.s

Therefore, Pressure Flow is $5.54 \times 10^{-13} \mathrm{~m}^{3} / \mathrm{s}$

Leak flow $\left(Q_{l}\right)=\frac{1}{12 \eta} \frac{\Delta p}{\cos \emptyset} \frac{\pi D}{\cos \emptyset} \delta^{3}[1]$

$\mathrm{H}=\delta=$ Depth of silt

$\mathrm{e}=$ width of screw flight

Note: Leak flow is small compared with drag flow and pressure flow and may be neglected in finding total flow

\section{D.7. Design of Barrel}

An efficient barrel cooling system is important to control the tendency for mechanical shear heat developed in the melt to override the electrical heater controls. The optimal extruder barrel length is 30-32 times its internal diameter $(30: 1 \mathrm{~L} / \mathrm{D}$, 32:1 L/D). Although shorter barrels can be used, mixing efficiency and melt uniformity are not optimal. Cooling to the extruder feed throat is critical to prevent surging or bridging. Internal cooling to the screw is not needed.

\section{Assumptions}

The outer diameter and internal diameter of barrel is chosen as $\mathbf{8 8 m m}$ and $73 \mathrm{~mm}$ respectively, therefore length of barrel will be $73 \mathrm{~mm}$ times 32 which is equal to $2336 \mathbf{m m}$. The thickness of the barrel is $15 \mathrm{~mm}$ to withstand the escape of heat through the barrel.

\section{D.8. Design of Heating Bands}

The mixture of the plastic and wood material must be processed at a temperature at or below the thermal degradation of the wood fibres, normally 200 to $220^{\circ} \mathrm{C}$ (392 to $428^{\circ} \mathrm{F}$ ) 
[11], most plastics are processed between temperatures between $163^{\circ} \mathrm{C} \& 200^{\circ} \mathrm{C}$ even though melting can occur between 108 to $121^{\circ} \mathrm{C}$ [10]. The target temperature was chosen as $180^{\circ} \mathrm{C}$ for the barrel. Hence, in agreement with [11], the mixture must be raised from room temperature $\left(25^{\circ} \mathrm{C}\right)$ to the target temperature $\left(180^{\circ} \mathrm{C}\right)$. The polyethylene material acts as the binding agent in the mixture, it flows when heated allowing proper mixing of the mixture, the heat needed to raise the temperature of the material from $25^{\circ} \mathrm{C}-180^{\circ} \mathrm{C}$ is given as; $\mathrm{Q}_{25}{ }^{\circ} \mathrm{C}_{-180}{ }^{\circ} \mathrm{C}=\mathrm{MC}_{P} \Delta \mathrm{t}_{1}+\mathrm{ML}+\mathrm{MC}_{P} \Delta \mathrm{t}_{2}$ [11].

$\mathrm{M}=$ Mass of material

$C_{P}=$ specific heat capacity of polyethylene material (2.004 $\mathrm{KJ} / \mathrm{Kg} . \mathrm{K})$

$\mathrm{L}=$ Specific latent heat of fusion $(74.8 \mathrm{KJ} / \mathrm{Kg})$

$\mathrm{Q}=$

\section{$13.88 \times 2.004 \times(121-25)^{\circ} \mathrm{C}+13.88 \times$ $74.8+13.88 \times 2.004 \times(180-121)^{\circ} \mathrm{C}$}

$\mathrm{Q}=2670.29+1038.22+1641.12$

$\mathrm{Q}=5349.63 \mathrm{KJ}$

The heat source must be able to generate this amount of heat and the amount of heat that will be lost through the walls of the heating chamber.

Heat supply by source $=$ heat lost through the walls of the barrel + heat used in raising the temperature of the material.

Heat lost through the walls of the chamber (barrel) by conduction is given by;

$\mathrm{L}=$ length of the heating chamber (barrel) which is cylindrical in shape $=3.048 \mathrm{~m}$

$t_{h f}=$ temperature of the heating chamber (internal $)=180^{\circ} \mathrm{C}$

$t_{\text {cof }}=$ external temperature of the heating chamber $=25^{\circ} \mathrm{C}$

$K_{A}=$ thermal conductivity of the inside steel layer $=45 \mathrm{~W} / \mathrm{mK}$

$K_{B}=$ thermal conductivity of the insulating material of the heating elements $=0.23 \mathrm{~W} / \mathrm{mK}$

$K_{C}=$ thermal conductivity of the outside steel layer = $45 \mathrm{~W} / \mathrm{mK}$

$r_{1}=$ internal radius of the heating chamber $=0.0508 \mathrm{~m}$

$r_{2}=$ internal radius interface between the outer steel layer and the insulating layer $=0.0134 \mathrm{~m}$

$r_{3}=$ radius of the interface between the outer steel layer and the insulating layer $=0.0136 \mathrm{~m}$

$$
\begin{aligned}
& Q_{c}=\frac{2 \pi x 3.048(180-25)}{\left(\frac{\ln (0.0184)}{45}+\frac{\ln (0.0186)}{45}\right)} \quad[10] \\
& Q=\frac{A\left(t_{1}-t_{2}\right)}{\left(\frac{d_{A}}{K_{A}}+\frac{d_{B}}{K_{B}}+\frac{d C}{K_{C}}\right)}
\end{aligned}
$$

\section{PERFORMANCE TEST FOR THE MACHINE}

Following the design, fabrication and assembly of the machine, the performance of the single-screw extruder was evaluated. The machine was prepared for the extrusion operation by first switching on the heater (i.e. the heating element). The heating lasted for $45 \mathrm{mins}$ to enable the barrel reach the heating temperature of $180^{\circ} \mathrm{C}$. The sorted samples comprising of both plastic and sawdust at different compositions was fed into the machine through the hopper, as the electric motor was simultaneously switched on. The time taken for recycling per batch was monitored with the use of a stop watch. A 2-Hp-3-phase electric motor was used as prime movers at specific periods of time. The time taken to recycle each quantity of plastic and sawdust varied from 5 to 10 minutes for each of the prime movers, the average performance of the machine is estimated to be $84.75 \%$ and the average capacity of the machine is estimated as $15.79 \mathrm{~kg} / \mathrm{hr}$. The test runs were carried out 6 times to obtain the performance of the machine and were replicated three times. The samples of the Wood-Plastic Composites produced were kept in a bucket of water to cool, and were weighed to determine the amount of plastic and sawdust that was recycled. Some physical and mechanical properties of the wood-plastic composites produced were determined using standard procedures.

\section{DISCUSSION OF RESULTS}

\section{A. Performance Evaluation of Extruder Results}

The designed Single Screw Extruder was constructed as shown in figure 4 below. The results of the performance evaluation showed that the machine performed at efficiency of $85 \%$. Analyzed data from the test runs define the characteristics of the machine, which showed that the machine is $87 \%$ efficient when performing the task at low speed of 4rpm with an average throughput of $14.04 \mathrm{~kg} / \mathrm{hr}$. When the machine was operated at a speed of $50.25 \mathrm{rpm}$, the efficiency was found to be $82 \%$ with a throughput of $17.55 \mathrm{~kg} / \mathrm{hr}$ and a low specific mechanical energy of $191.21 \mathrm{~kJ} / \mathrm{hr}$ was achieved as expected to save running cost and high energy consumption. 


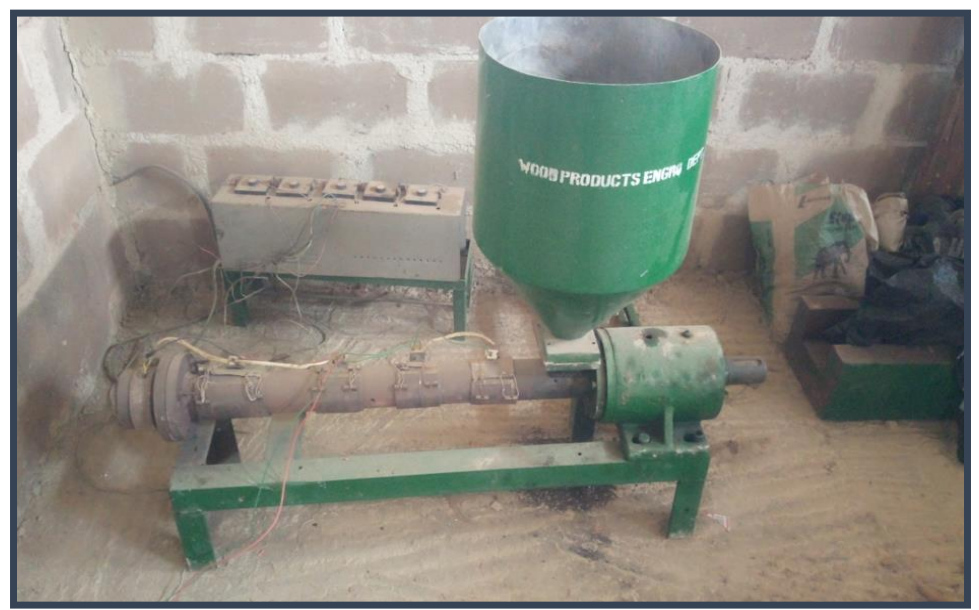

Fig. 5: Locally fabricated Single Screw Extruder Machine

Figure 5 illustrates that the higher the output mass the lower the SME at low speed. This explains that with an increase in wood content in the composites, the SME is higher.

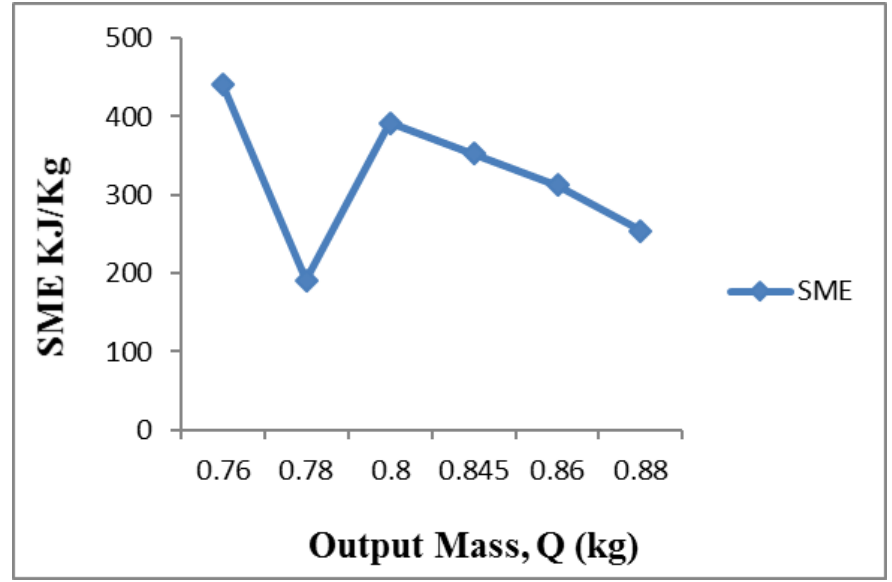

Figure 6: The Effect of Mass Output on the Specific Mechanical Energy under the Influence of Screw Speed and Torque

The results showed that the lowest and highest specific mechanical energy was at an output mass of 0.78 and 0.76 respectively. Although the SME reduces with increasing output mass. The use of a lower speed for the operation of the machine will result to an increase in output mass because the loss of the material during operation will be minimal; therefore, lower speeds results in lower specific mechanical energy.

The results showed that to achieve the highest throughput, the output mass must be $0.78 \mathrm{~kg}$. The throughput increases with increasing output mass.

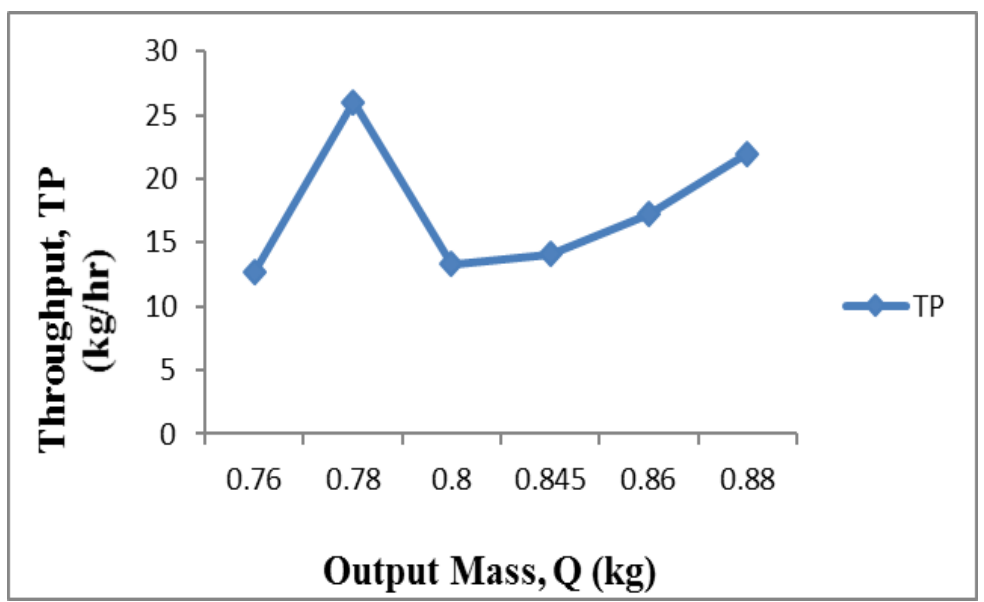

Figure 7: The Effect of Mass Output on the Throughput of the Machine under the Influence of Screw Speed and Torque

\section{B. Wood-Plastic Composite Test}

The results of various tests carried out to determine the mechanical and physical property of the wood-plastic composite is presented in Tables 1, 2, 3 and Figure 7.

\section{B.1. Density and Weight}

The volume of each sample was estimated from the nominal dimensions while the mass was determined using a weighing scale. The density of all samples was calculated in $\mathrm{g} / \mathrm{mm}^{3}$.

From the results presented in Table 1, it can be deduced that wood-plastic composites are less dense compared to regular wood due to its lesser weight. WPCs are less dense than water as they tend to float on water. The difference in the densities of the sample is as a result of variations in the wood content.

\section{B.2 Thickness Swelling}

Table 2 shows the increase in thickness of the samples when soaked in water at 0 hours, 2 hours and 24 hours. Sample A has the lowest \% increase which is due to the fact that there is no fibre/sawdust in the sample. The variation in the thickness was as a result of the difference in the composition of the samples. Wood is a hygroscopic material i.e. it absorbs moisture readily. Samples with higher wood content absorb more water.

From the Table 3, sample A which is without fibre or sawdust in composition has the lowest value for water absorption with little or no difference in the 2hours and 24hours period of soaking in water. Although other samples have low water absorption, there are significant differences in the initial (2hrs) and final (24hrs) period. When wood content increases beyond $60 \%$, the resulting water absorption will increase accordingly because the wood is less likely to be fully encapsulated by the 
Table 1: Mean Weight, Dimensions and Density of Samples

\begin{tabular}{|c|c|c|c|c|c|c|c|c|}
\hline \multirow{2}{*}{$\begin{array}{c}\text { Sample (Plastic/Wood } \\
\text { ratio) }\end{array}$} & \multicolumn{3}{|c|}{ Dimension (mm) } & \multirow{2}{*}{$\begin{array}{l}\text { Diameter } \\
(m m)\end{array}$} & \multirow{2}{*}{$\begin{array}{c}\text { Area } \\
\left(\mathrm{mm}^{2}\right)\end{array}$} & \multirow{2}{*}{$\begin{array}{l}\text { Volume } \\
\left(\mathrm{mm}^{3}\right)\end{array}$} & \multirow{2}{*}{$\begin{array}{l}\text { Weight } \\
(g)\end{array}$} & \multirow{2}{*}{$\begin{array}{l}\text { Density } \\
\left(\mathrm{g} / \mathrm{mm}^{3}\right)\end{array}$} \\
\hline & Length & Breadth & Thickness & & & & & \\
\hline$A(100 / 0)$ & & & 13 & 65 & 3318.7 & 43143.1 & 780 & 0.0181 \\
\hline B $(90 / 10)$ & & & 14 & 65 & 3318.7 & 46461.8 & 880 & 0.0189 \\
\hline $\mathrm{C}(80 / 20)$ & 102 & 40 & 13 & & 4080 & 53040 & 860 & 0.0162 \\
\hline D (70/30) & 113 & 43 & 17 & & 4859 & 82603 & 845 & 0.0102 \\
\hline $\mathrm{E}(60 / 40)$ & 144 & 42 & 19 & & 6048 & 114912 & 800 & 0.007 \\
\hline F (50/50) & 134 & 42 & 17 & & 5628 & 95676 & 760 & 0.0079 \\
\hline
\end{tabular}

Table 2: Percentage Increase in Thickness at $0 \mathrm{hrs}, 2 \mathrm{hrs}$ and $24 \mathrm{hrs}$

\begin{tabular}{|c|c|c|c|c|c|}
\hline \multirow{2}{*}{$\begin{array}{c}\text { Sample (Plastic/Wood } \\
\text { ratio) }\end{array}$} & \multicolumn{3}{|c|}{ Thickness } & \multirow{2}{*}{$\begin{array}{c}\% \text { increase in } \\
\text { thickness after } 2 \mathrm{hrs}\end{array}$} & \multirow{2}{*}{$\begin{array}{c}\text { \% increase in thickness } \\
\text { after } 24 \mathrm{hrs}\end{array}$} \\
\hline & Ohrs & $2 \mathrm{hrs}$ & $24 \mathrm{hrs}$ & & \\
\hline$A(100 / 0)$ & 13 & 13.14 & 13.18 & 1.08 & 1.38 \\
\hline B (90/10) & 14 & 14.3 & 14.3 & 2.14 & 2.14 \\
\hline $\mathrm{C}(\mathbf{8 0} / \mathbf{2 0})$ & 13 & 13.3 & 13.31 & 2.31 & 2.38 \\
\hline$D(70 / 30)$ & 17 & 17.4 & 17.41 & 2.35 & 2.41 \\
\hline$E(60 / 40)$ & 19 & 19.4 & 19.41 & 2.11 & 2.16 \\
\hline$F(50 / 50)$ & 17 & 17.5 & 17.52 & 2.94 & 3.06 \\
\hline
\end{tabular}

Table 3: Water Absorption Results after 0 hours, 2hours and 24hours

\begin{tabular}{|c|c|c|c|c|c|c|c|}
\hline \multirow{2}{*}{$\begin{array}{c}\text { Sample (Plastic/Wood } \\
\text { ratio) }\end{array}$} & \multicolumn{3}{|c|}{ Weight (g) } & \multicolumn{2}{|c|}{ Water absorption } & \multirow[t]{2}{*}{ Area } & \multirow{2}{*}{$\begin{array}{l}\mathrm{CAC}, \mathrm{k} \\
\left(10^{-7}\right) \\
\end{array}$} \\
\hline & Ohrs & $2 \mathrm{hrs}$ & $24 \mathrm{hrs}$ & $\begin{array}{c}\% \text { increase after } \\
2 \mathrm{hrs}\end{array}$ & $\begin{array}{c}\% \text { increase after } \\
24 \mathrm{hrs}\end{array}$ & & \\
\hline$A(100 / 0)$ & 780 & 780.2 & 780.2 & 0.03 & 0.03 & 3318.7 & 2.05 \\
\hline B $(90 / 10)$ & 880 & 880.2 & 880.3 & 0.02 & 0.03 & 3318.7 & 3.08 \\
\hline$C(80 / 20)$ & 860 & 860.3 & 860.4 & 0.03 & 0.05 & 4080 & 3.34 \\
\hline D (70/30) & 845 & 845.6 & 845.7 & 0.07 & 0.08 & 4859 & 4.90 \\
\hline$E(60 / 40)$ & 800 & 800.8 & 800.9 & 0.1 & 0.11 & 6048 & 5.06 \\
\hline F $(50 / 50)$ & 760 & 761 & 761.1 & 0.13 & 0.14 & 5628 & 6.65 \\
\hline
\end{tabular}

$* C A C=$ capillarity absorption coefficient. 
matrix polymer. Water absorption of composite is an important factor in classifying its durability and composites of low water absorption will afford better protection to reinforcement within it (Taha et al, 2008).

\section{B.3. Compressive Strength}

The compressive strength test was carried out on six composite samples in the air dry condition by gradually applying and increasing load to ascertain its crushing point. These tests were carried out using a compressive testing machine. The samples were loaded to the point of failure to determine its compressive strength and load.

From Figure 6, it can be inferred that the compressive strength increases with respect to an increasing percentage of wood fibre and/or sawdust in the composite. According to [3], the greater the wood component the greater the stiffness of the wood composite which is proportional to which is proportional to the load it can support.

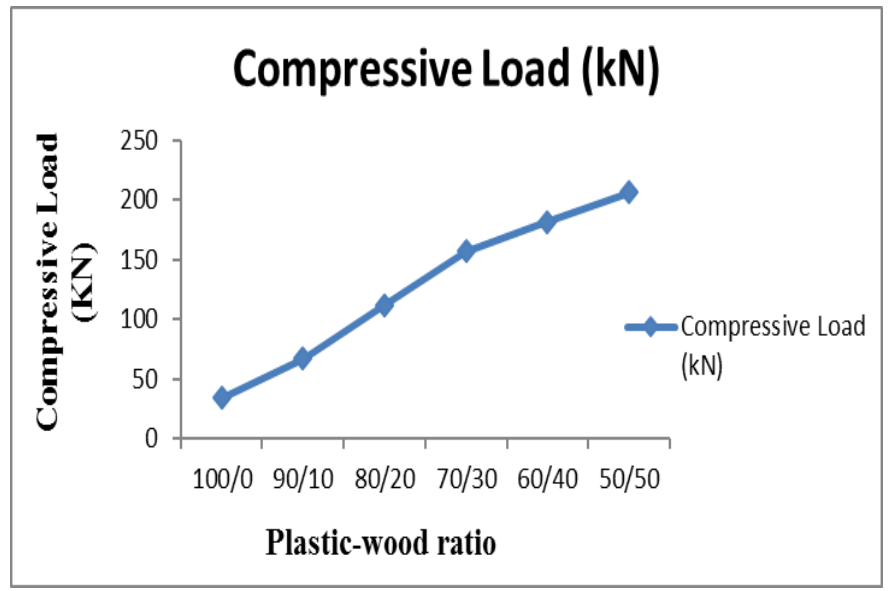

Fig 8: Graph of Compressive Strength Test

\section{Test Inference}

The compressive strength tests properties were higher compared to those of sawn lumber, i.e. the compression perpendicular to grain. Density depended on the wood to plastic ratio which explains the trend of increasing compressive strength and density. Generally, the compression strength is greater in samples of higher wood content and increased with density of the composites.

Also the proportion of wood to plastic in the composite, determines the strength of the composite. This difference in strength properties is seen in the different mixing ratios. The addition of wood component enhances the stiffness; however, they become more brittle.

The fungal resistance and dimensional stability of woodplastic composites is better than solid wood because they absorb moisture more slowly due to the thermoplastic matrix.
The thickness swelling test and water absorption test showed that wood-plastic composite absorb moisture more slowly or if not at all depending on the ratio of wood to plastic in the composite. This makes wood-plastic composites more suitable for outdoor purposes than solid wood. Although the mechanical properties such as creep resistance, stiffness and strength are lower than those of solid wood. Therefore, woodplastic composites are suitable for non-structural members in building applications.

\section{CONCLUSION}

The study shows that a single screw extruder designed and fabricated, can be used for recycling waste pure water sachets, plastic bottles and sawdust.

The modifications introduced in the design and operation of the single screw extruder, if implemented, will be beneficial and advantageous in the following ways:

- The processing of waste plastic materials will be enhanced to achieve the production of high quality wood-plastic products on relatively large scale for domestic and industrial uses.

- Labour, fatigue and cost involved in the production of wood-plastic will reduce.

\section{RECOMMENDATIONS}

The fabricated single-screw extruder is suitable for developing countries as it helps in alleviating environmental pollution caused by improper waste disposal and management. It also serves as a good source of employment which requires low start-up capital. I recommend this machine to small-scale business owners and individuals who are unemployed. In order to improve the efficiency and productivity of the extruder the following recommendations are made:

- That an electrical panel be introduced to separately control the temperature and pressure of the heating bands.

- That a thermocouple be installed to shut down the heating bands when they attain the required temperature to prevent overheating.

- That a lever should be installed to the pulley as an alternative to the electric motor.

- That the barrel should be insulated to reduce heat loss to the environment, thereby making the process more efficient.

- That a better cooling system be introduced to considerably reduce the temperature of the products as they come out from the die.

- Mechanical cutting device should be incorporated to cut the products in to the required dimension as they come out of the die.

- Mould can be connected to the die to collect the extrudate. 


\section{References}

[1] Anonymous (1955). Description and analysis of polymer flow in extruders. http:// www.kmutt.ac.th/p-prof/PPROF\%2520w... Cited on 28/10/2014.

[2] Brandrup J., Recycling and recovery of plastics. 1996: Hanser Verlag.

[3] Douglas J.G. and David Murdock. (2002). Extrusion of wood plastic composites. Advanced engineered wood composites center, University of Maine, Orono, Maine 04469.

[4] Einwood (2010) Wood plastic composites: a material of the future.

[5] Khurmi R.S. and Gupta J.K. (2005). A Textbook of Machine Design.

[6] Kristiina Niska O. and Mohini Sain. Wood polymer composites 2008.

[7] Maiju Hietala. (April 2011). Extrusion processing of wood raw materials for use in wood-polymer composites.

[8] Nwaigwe K.N, Nzediegwe .C, Ugwuoke P.E. (2012). Design, Construction and Performance Evaluation of a Modified Cassava Milling Machine. Research Journal of Applied Sciences, Engineering and Technology 4(18): 3354-3362.2012 ISSN: 2040-7467, C Maxwell Scientific Organization, 2012.

[9] Odior A.O., Oyawale Festus A. and Odusote Joe K. (2012). Development of a polythene recycling machine from locally sourced materials. Industrial Engineering Letters, ISBN 2225-0581 (online), Vol 2, No. 6, 2012. Pp $42-46$

[10] Ugoamadi C.C. and Ihesiulor O.K. (2011). Optimization of the development of a plastic recycling machine. Nigerian Journal of technology, Vol 30, No 3.

[11] Wood Handbook (2010). Wood as an Engineering material, April 2010.

\section{Creative Commons Attribution License 4.0 (Attribution 4.0 International, CC BY 4.0)}

This article is published under the terms of the Creative Commons Attribution License 4.0

https://creativecommons.org/licenses/by/4.0/deed.en_US 